\title{
Alcohol consumption and breast tumor gene expression
}

\author{
Jun Wang ${ }^{1,2^{*}}$ (D), Yujing J. Heng ${ }^{3}$, A. Heather Eliassen ${ }^{4,5}$, Rulla M. Tamimi ${ }^{4,5}$, Aditi Hazra ${ }^{6}$, Vincent J. Carey ${ }^{4}$, \\ Christine B. Ambrosone ${ }^{7}$, Victor P. de Andrade ${ }^{8}$, Adam Brufsky ${ }^{9}$, Fergus J. Couch ${ }^{10}$, Tari A. King ${ }^{11}$, \\ Francesmary Modugno ${ }^{12}$, Celine M. Vachon ${ }^{13}$, David J. Hunter ${ }^{4,5,14}$, Andrew H. Beck ${ }^{3 \dagger}$ and Susan E. Hankinson ${ }^{1,4,5+}$
}

\begin{abstract}
Background: Alcohol consumption is an established risk factor for breast cancer and the association generally appears stronger among estrogen receptor (ER)-positive tumors. However, the biological mechanisms underlying this association are not completely understood.

Methods: We analyzed messenger RNA (mRNA) microarray data from both invasive breast tumors $(N=602)$ and tumor-adjacent normal tissues $(N=508)$ from participants diagnosed with breast cancer in the Nurses' Health Study (NHS) and NHSII. Multivariable linear regression, controlling for other known breast cancer risk factors, was used to identify differentially expressed genes by pre-diagnostic alcohol intake. For pathway analysis, we performed gene set enrichment analysis (GSEA). Differentially expressed genes or enriched pathway-defined gene sets with false discovery rate $(F D R)<0.1$ identified in tumors were validated in RNA sequencing data of invasive breast tumors $(N=166)$ from The Cancer Genome Atlas.
\end{abstract}

Results: No individual genes were significantly differentially expressed by alcohol consumption in the NHS/NHSII. However, GSEA identified 33 and 68 pathway-defined gene sets at FDR $<0.1$ among 471 ER+ and 127 ER- tumors, respectively, all of which were validated. Among ER+ tumors, consuming 10+ grams of alcohol per day (vs. 0) was associated with upregulation in RNA metabolism and transport, cell cycle regulation, and DNA repair, and downregulation in lipid metabolism. Among ER- tumors, in addition to upregulation in RNA processing and cell cycle, alcohol intake was linked to overexpression of genes involved in cytokine signaling, including interferon and transforming growth factor (TGF)- $\beta$ signaling pathways, and translation and post-translational modifications. Lower lipid metabolism was observed in both ER+ tumors and ER+ tumor-adjacent normal samples. Most of the significantly enriched gene sets identified in ER- tumors showed a similar enrichment pattern among ER- tumor-adjacent normal tissues.

Conclusions: Our data suggest that moderate alcohol consumption (i.e. 10+ grams/day, equivalent to one or more drinks/day) is associated with several specific and reproducible biological processes and pathways, which adds potential new insight into alcohol-related breast carcinogenesis.

Keywords: Alcohol, Prospective, Epidemiology, Breast tumor, Gene expression

\footnotetext{
* Correspondence: junw@usc.edu

${ }^{\dagger}$ Equal contributors

${ }^{1}$ Department of Biostatistics and Epidemiology, School of Public Health and Health Sciences, University of Massachusetts Amherst, 715 N Pleasant Street, Amherst, MA 01003, USA

${ }^{2}$ Present address: Department of Preventive Medicine, University of Southern California, Harlyne J. Norris Research Tower, 1450 Biggy Street, Los Angeles, CA 90033, USA

Full list of author information is available at the end of the article
} 


\section{Background}

Alcohol consumption is an established breast cancer risk factor [1]. Large prospective cohort studies have reported a modest but significant increase in risk $(8-9 \%)$ per $10 \mathrm{~g}$ of alcohol consumed per day [1,2]. Specifically, in the Nurses' Health Study (NHS) with long-term average alcohol consumption, the risk increased by $15 \%$ (95\% confidence interval (CI) 1.06-1.24) for 5.0-9.9 g/ day of alcohol and by $51 \%$ (95\% CI 1.35-1.70) for at least $30 \mathrm{~g} /$ day of alcohol, compared to women who did not drink [3]. The positive association was observed in both estrogen receptor (ER)-positive (ER+) and ERnegative (ER-) tumors but appeared stronger with ER+ than with ER- tumors [3, 4].

The mechanism underlying the alcohol and breast cancer association is not completely understood. One major hypothesis is that this association is mediated, at least in part, through estrogen metabolism [5, 6]. Other hypothesized mechanisms include the generation of acetaldehyde and reactive oxygen species (ROS) during alcohol metabolism [7]. Acetaldehyde has been classified as a carcinogen by the International Agency for Research on Cancer (IARC) [8] and, after alcohol administration, accumulation of acetaldehyde was observed in rat mammary tissue in experimental studies $[9,10]$. Ethanol oxidation can lead to generation of ROS in rat mammary tissue $[9,10]$ and ROS promotes many aspects of tumor development and progression [11]. In addition, disruption of folate metabolism and DNA and/or histone hypomethylation have been hypothesized to be involved in alcohol-mediated carcinogenesis [8]. However, despite these hypotheses, no definitive mechanisms have yet been identified.

Assessment of molecular and/or genetic markers in breast tumor tissues may provide insights into the underlying mechanism(s) for established breast cancer risk factors. Recent studies evaluating breast tumor genome-wide gene expression profiling have identified molecular signatures associated with several established risk factors, such as body mass index (BMI) [12] and parity [13]. However, to date, no studies have assessed alcohol-related molecular signatures in breast tumors. To help unravel the underlying mechanisms of alcohol consumption and breast cancer risk, we evaluated the association between pre-diagnostic alcohol consumption and genome-wide gene expression in breast tumor and tumor-adjacent normal tissue in the prospective NHS and NHSII, and further validated our results in an independent validation dataset obtained from The Cancer Genome Atlas (TCGA) [14]. We hypothesized that the biological pathways underlying the association between alcohol and breast cancer could vary by tumor ER status and thus conducted the analysis by tumor ER expression.

\section{Methods}

\section{Study population}

The NHS was established in 1976 when 121,700 US female registered nurses, aged 30-55 years, completed an initial mailed questionnaire, and the NHSII was established in 1989, when 116,429 US female registered nurses, aged 25-42 years, completed and returned an initial questionnaire. Both cohorts have been followed biennially by mailed questionnaire to update information on exposure status and ascertain newly diagnosed diseases, including cancers. All women reporting incident diagnoses of breast cancer were asked for permission to review their medical records; cases for which pathology reports were obtained were confirmed by medical record review (>99\%).

For this analysis, we included invasive breast cancer cases with both sufficient RNA from formalin-fixed paraffin-embedded (FFPE) tumor blocks for expression profiling and with available blood samples (the latter criterion to maximize the utility of the subset of cases that could be arrayed). Upon meeting the two criteria, in the NHS, we identified 532 invasive postmenopausal cases diagnosed in 1990-2004 which were a subset of the Cancer Genetic Markers of Susceptibility (CGEMS) initiative [15]; in the NHSII, invasive cases, regardless of menopausal status, diagnosed in 1995-2009 in the NHSII $(\mathrm{N}=280)$ were included. Archived FFPE breast tumor blocks were obtained from the cohort tumor tissue repository; details of breast tumor tissue block collection have been described previously $[16,17]$. Although only a subset of all the eligible cases were included in the TMA (primarily because either the tumor blocks had been destroyed by the hospital or there was insufficient tumor in the block), in each cohort, the characteristics of participants included in the TMA were very similar to those of all the eligible cases, including alcohol consumption and other breast cancer risk factors (e.g. first-degree family history, BMI and parity). The study was approved by the Committee on the Use of Human Subjects in Research at the Brigham and Women's Hospital.

\section{Assessment of alcohol exposure and other covariates}

The assessment of alcohol consumption has been reported in detail elsewhere [3]. Briefly, information was first collected in 1980 in the NHS and in 1991 in the NHSII when participants reported their average frequency of intake for each alcoholic beverage (i.e. beer, wine, and liquor) during the previous 12 months through a semi-quantitative food frequency questionnaire, which was updated every 2-4 years thereafter in each cohort. Alcohol intake (grams per day) was calculated as the sum of the daily number of drinks multiplied by the average alcohol content of each beverage 
type (12.8 g per beer, $11.0 \mathrm{~g}$ per glass of wine, and $14.0 \mathrm{~g}$ per serving of liquor). We then calculated cumulative average intake by averaging alcohol consumption over time using all available information beginning in 1980 (NHS) or 1991 (NHSII). We also evaluated recent alcohol intake using information from the questionnaire cycle before diagnosis (i.e. 2-4 years before diagnosis). Cumulative average and recent alcohol consumption were highly correlated (Spearman $r=0.87$ ) and results were very similar when using either cumulative average or recent alcohol; thus we presented results from recent alcohol intake. Covariate data, including parity, family history of breast cancer, BMI (weight $(\mathrm{kg}) /$ height $\left.(\mathrm{m})^{2}\right)$, menopausal status and menopausal hormone therapy (MHT) use were obtained from the NHS or NHSII questionnaire at baseline and subsequent biennial questionnaires; for BMI, menopausal status and MHT use, the information taken from the most recent questionnaire was used.

\section{Gene expression microarray and quality control analysis} RNA was extracted from multiple cores of 1 or $1.5 \mathrm{~mm}$ taken from tumor ( $N=3$ cores) or adjacent normal $(N=$ 5 cores) tissues from FFPE blocks using the Qiagen AllPrep RNA isolation kit. Tumor-adjacent normal tissue was generally $>1 \mathrm{~cm}$ from the tumor edge. Since FFPE samples are known to have variable yields, tissues from all the cores from the same patient were placed into one microtube to maximize RNA yield. Total RNA was used to synthesize double-stranded complementary DNA which was then fragmented and hybridized to Affymetrix Glue Grant Human Transcriptome Array [18] (HTA 3.0v1 pre-release version from Affymetrix, Santa Clara, CA, USA). We included four independent breast tumor samples as technical replicates (identified from Beth Israel Deaconess Medical Center, Boston, MA, USA) in each assay plate; the correlation of these replicates across all arrays was $\geq 0.93$.

Gene expression data were normalized and summarized using robust multiarray average (RMA; Affymetrix Power Tools (APT) v1.18.0). Out of the total 1324 tumor and tumor-adjacent normal specimens (934 and 390 in the NHS and NHSII, respectively), we excluded 131 (14\%) and 43 (11\%) from the NHS and NHSII, respectively, with an area under the curve (AUC) $<0.55$ (evaluated using APT probeset summarization-based metrics) and further excluded 40 that failed the non-outlier analysis by arrayQualityMetrics v3.24.0 [19], leaving 1110 samples (602 tumors and 508 tumor-adjacent normal samples) for analysis. Although tumor specimens from the NHS were generally older than those from the NHSII, the proportions filtered out according to RNA quality (i.e. $14 \%$ vs. $11 \%)$ were similar in the two cohorts. Non-specific filtering by median expression levels was used to remove the bottom $25 \%$ of expressed probes, leaving 25,979 genelevel annotated transcript clusters included in the analysis. Gene expression data were deposited into the Gene Expression Omnibus [GEO: GSE93601].

We also assessed biological concordance (i.e. probe expression concordance with protein markers measured by immunohistochemical (IHC) staining) for select probes. We confirmed the correlation between probes for ESR1, PGR, and ERBB2 with IHC markers, ER, progesterone receptor (PR), and human epidermal growth factor receptor 2 (HER2), in tumors to confirm biological reproducibility of the data (Additional file 1: Figure S1).

\section{Statistical analysis}

We performed analyses at the level of both probes and pathway-defined gene sets (Fig. 1). All analyses were conducted separately in ER+ tumors, ER+ tumoradjacent normal tissues, and ER- tumors and ERtumor-adjacent normal tissues. We conducted multivariable linear regression using the $\mathrm{R}$ Bioconductor package linear models for microarray data (LIMMA) [20] for 25,979 probes. To maximize power, samples from the NHS and NHSII were pooled in all analyses (although NHS and NHSII samples were run on different plates, all samples were normalized together) and we adjusted for microarray plate, thus controlling for both cohort and plate, in the regression models. Alcohol consumption was defined as a three-category variable: $0,>0$ to $<$ 10 and $10+\mathrm{g} /$ day. Factors correlated with alcohol consumption and/or those known to affect tumor gene expression were evaluated as potential covariates in the regression models. Age at diagnosis, year of diagnosis, microarray plate, first-degree family history of breast cancer and recent BMI were included in the final models presented here. Although smoking status is often correlated with alcohol intake, smoking was not adjusted for in the analysis because so few women $(\sim 8 \%)$ were current smokers 2-4 years before diagnosis. In the single-probe analysis ( $N=25,979$ probes), individual probes were considered significantly differentially expressed by alcohol intake using a false discovery rate (FDR) threshold: FDR $<0.1$ for tumors and FDR $<0.05$ for tumor-adjacent normal tissues (due to the lack of a validation dataset of tumor-adjacent normal samples, a more stringent FDR threshold was applied).

To incorporate biological knowledge into the analysis, we further performed gene set enrichment analysis (GSEA) [21] to identify pathway-defined gene sets that varied by alcohol intake. Gene sets were collected from the Molecular Signatures Database (MSigDB) (http://www.broadinstitute.org/gsea/msigdb/), including 217 from BioCarta, 186 from Kyoto Encyclopedia of Genes and Genomes (KEGG), 674 from Reactome, and 825 from Gene Ontology (GO) biological process; those with $<15$ genes or $>500$ genes 


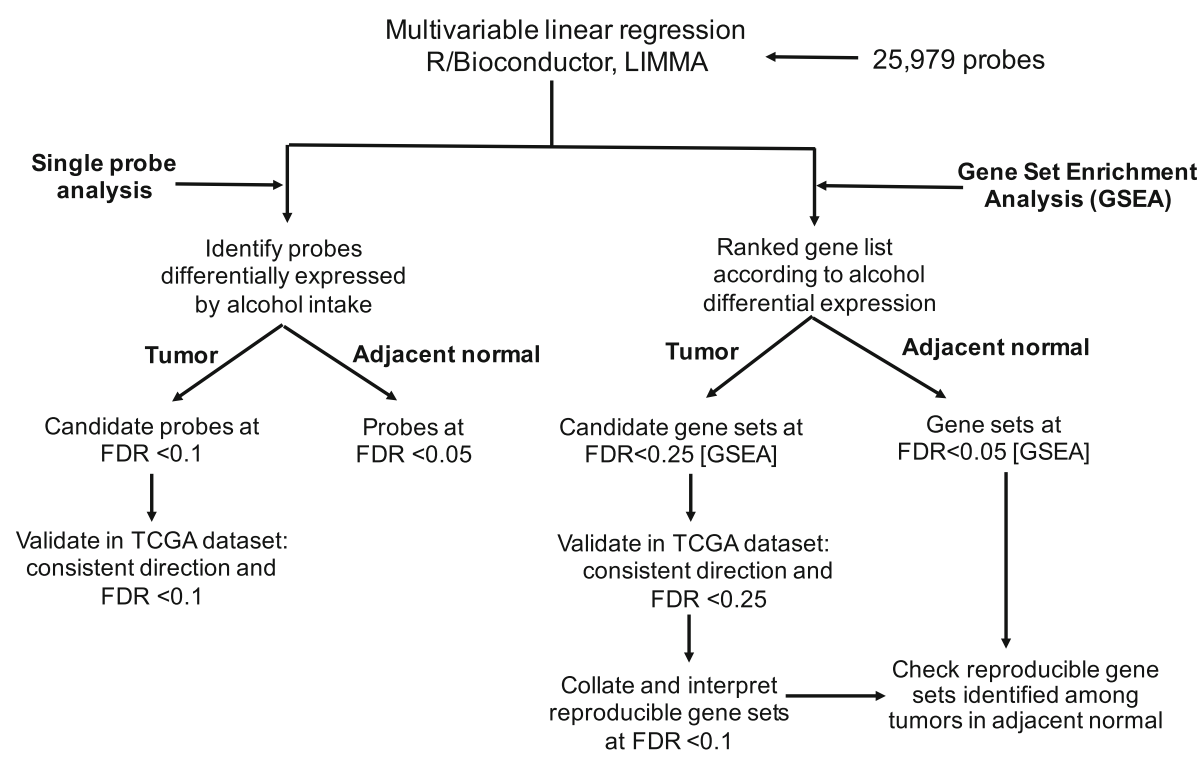

Fig. 1 Analysis strategy for identifying differentially expressed probes or enriched pathway-defined gene sets in the Nurses' Health Study (NHS) and the NHSII. FDR false discovery rate, LIMMA linear models for microarray data

were filtered out, leaving 1293 pathway-defined gene sets in the analysis. The four pathway databases were included because each has a distinct but also complementary approach to capture known biological pathways [22]. We used the GSEA "Pre-ranked" function and imported ranked gene lists according to the alcohol-associated $t$ statistic from the regression models. In the pathway analysis, only probes that are annotated as a gene ( $N=15,407$ probes) were included in the GSEA. Briefly, all the genes were first ranked according to the alcohol-associated $t$ statistic; an enrichment score was then calculated for each gene set. The enrichment score corresponds to a weighted Kolmogorov-Smirnov-like statistic and reflects the extent to which the gene set is overrepresented at the extreme (i.e. top or bottom) of the entire ranked list [21]. If the enrichment score is positive (e.g. the gene set is overrepresented by top ranked genes), then the gene set is considered upregulated while it is considered downregulated if the score is negative. In the discovery stage, among tumors, gene sets at FDR $<0.25$ were considered significantly enriched. Again, a more stringent FDR threshold (i.e. FDR $<0.05$ ) was applied to tumor-adjacent normal samples. We further performed leading-edge subset analysis to identify the core set (i.e. key genes) of the gene set that accounted for the enrichment signal [21].

\section{Validation analysis}

The validation dataset consisted of RNA sequencing (RNA-Seq) data from 166 invasive breast tumors, a subset of breast tumor samples from TCGA that had prediagnostic alcohol consumption (generally defined as recent intake) and comparable covariate data. For the validation dataset, we originally contacted six TCGA sites with the largest number of potential cases and four of them agreed to collect or provide already available breast cancer risk factor data, including the University of Pittsburgh, Roswell Park Cancer Institute, the Mayo Clinic and Memorial Sloan Kettering Cancer Center. A total of 220 invasive cases had RNA-Seq data and at least some of the key covariates (e.g. BMI or alcohol or parity), of which 166 had complete information on alcohol consumption and covariates that were required for adjustment in the regression models. TCGA RNA-Seq data were previously processed using the MapSplice algorithm [23] to perform the alignment and RNA-Seq by expectation maximization (RSEM) [24] to estimate gene abundance. The expression dataset included 20,531 genes; in the differential expression analysis, genes with low expression (i.e. $<25^{\text {th }}$ percentile) according to median counts per million were removed, leaving 15,398 unique genes. The common genes in the NHS/NHSII and the TCGA dataset accounted for approximately $84 \%$ of all the genes in each dataset. The RNA-Seq data were normalized using the trimmed mean of M-values [25] and $\log$-transformed with associated precision weights using Voom. Multivariable linear regression implemented through R/Bioconductor LIMMA was then used to identify genes that were differentially expressed by recent alcohol intake and we further performed GSEA using similar methods as in the NHS/NHSII.

To validate the significantly enriched pathway-defined gene sets identified in the NHS/NHSII, we required that these gene sets showed a consistent direction (i.e. same upregulation or downregulation) of enrichment and an FDR $<0.25$ in the TCGA dataset (Fig. 1). Among those 
replicated gene sets, we only reported gene sets at FDR $<0.1$ in the NHS/NHSII. No validation dataset of breast normal or tumor-adjacent normal samples with alcohol consumption information was available and thus it was not feasible for us to replicate our results in further datasets.

\section{Results}

In the NHS and NHSII, the average alcohol intake was relatively low (mean $6.4 \mathrm{~g} /$ day, SD 11.4). Approximately $34 \%$ of the women had no recent alcohol consumption and $45 \%$ women consumed $<10 \mathrm{~g}$ of alcohol per day and only $21 \%$ women consumed $10+$ g/day of alcohol. Age at diagnosis and parity were roughly evenly distributed across categories of recent alcohol intake. Women with higher alcohol intake were less likely to have a first-degree family history of breast cancer, had lower BMI and were diagnosed in more recent years (Table 1). Among women with natural menopause or bilateral oophorectomy, those with alcohol intake at least $10 \mathrm{~g} /$ day were less likely to use MHT compared to women with no or lower alcohol intake. Out of the 602 tumor specimens, 445 (74\%) had matched adjacent normal tissues. The characteristics of women with tumor-adjacent normal samples were similar to those with only tumor specimens available (data not shown). Alcohol consumption and other risk factors such as age at diagnosis and BMI were similar between women diagnosed with ER+ tumors and those with ER- tumors (Table 2). Compared to ER+ tumors, ER- tumors tended to be larger, moderately or poorly differentiated, and diagnosed at a later stage.

Patients with invasive breast cancer in the validation dataset (i.e. TCGA) were younger at diagnosis, had a higher BMI, were less likely to drink alcohol and were diagnosed more recently (i.e. 2005-2009), compared to those in the NHS/NHSII (Additional file 2: Table S1). In addition, the TCGA dataset included a greater percentage of premenopausal women than the NHS/NHSII dataset (38\% vs. 17\%); among postmenopausal women, those in the TCGA dataset were less likely to use MHT than women in the NHS/NHSII dataset. While the majority of the TCGA tumors were stage II or III, about $60 \%$ of the tumors in the NHS/NHSII were stage I. Similar to the NHS/NHSII, in TCGA, women with higher alcohol intake (i.e. 1+ drink per day) had a lower BMI, were less likely to have a first-degree family history of breast cancer, and tended to be premenopausal/ perimenopausal and were diagnosed in more recent years (i.e. 2008-2011), compared to women with lower alcohol intake (Additional file 2: Table S2).

Table 1 Characteristics of patients with invasive breast cancer according to recent alcohol consumption in the NHS and the NHSII

\begin{tabular}{|c|c|c|c|c|c|c|}
\hline & \multicolumn{6}{|c|}{ Recent alcohol consumption, g/day } \\
\hline & \multicolumn{2}{|l|}{0} & \multicolumn{2}{|c|}{$>0$ to $<10$} & \multicolumn{2}{|l|}{$10+$} \\
\hline & \multicolumn{2}{|c|}{$N=206$} & \multicolumn{2}{|c|}{$N=267$} & \multicolumn{2}{|c|}{$N=126$} \\
\hline & Mean & SD & Mean & SD & Mean & SD \\
\hline Age at diagnosis, years & 61.6 & 9.6 & 59.9 & 9.0 & 62.3 & 9.8 \\
\hline $\mathrm{BMI}$ at diagnosis, $\mathrm{kg} / \mathrm{m}^{2}$ & 27.3 & 5.7 & 25.7 & 4.6 & 24.5 & 4.3 \\
\hline Parity & 2.6 & 1.7 & 2.7 & 1.7 & 2.5 & 1.9 \\
\hline Cumulative average alcohol $^{a}, \mathrm{~g} /$ day & 0.8 & 2.1 & 4.2 & 4.0 & 19.4 & 12.0 \\
\hline \multirow[t]{2}{*}{ Recent alcohol, g/day } & 0 & 0 & 3.7 & 2.6 & 22.9 & 16.0 \\
\hline & N & $\%$ & $\mathrm{~N}$ & $\%$ & N & $\%$ \\
\hline First-degree family history & 38 & 18.4 & 45 & 16.9 & 13 & 10.3 \\
\hline \multicolumn{7}{|l|}{ Menopausal at diagnosis } \\
\hline Premenopausal & 32 & 15.5 & 56 & 21.0 & 15 & 11.9 \\
\hline Postmenopausal & 169 & 82.0 & 203 & 76.0 & 108 & 85.7 \\
\hline Unknown & 5 & 2.4 & 8 & 3.0 & 3 & 2.4 \\
\hline Current MHT use ${ }^{\mathrm{b}}$ & 86 & 52.4 & 117 & 60.0 & 46 & 43.8 \\
\hline \multicolumn{7}{|l|}{ Year of diagnosis } \\
\hline 1990-1999 & 122 & 59.2 & 157 & 58.8 & 66 & 52.4 \\
\hline 2000-2004 & 66 & 32.0 & 90 & 33.7 & 52 & 41.3 \\
\hline 2005-2009 & 18 & 8.7 & 20 & 7.5 & 8 & 6.3 \\
\hline
\end{tabular}


Table 2 Study population and tumor characteristics by ER status in the NHS and the NHSII

\begin{tabular}{|c|c|c|c|c|}
\hline & \multicolumn{2}{|c|}{$\begin{array}{l}\text { ER+ tumors } \\
N=471\end{array}$} & \multicolumn{2}{|c|}{$\begin{array}{l}\text { ER- tumors } \\
N=127\end{array}$} \\
\hline & Mean & SD & Mean & SD \\
\hline Age at diagnosis, years & 61.4 & 9.6 & 59.1 & 8.9 \\
\hline $\mathrm{BMl}$ at diagnosis, $\mathrm{kg} / \mathrm{m}^{2}$ & 26.0 & 5.0 & 26.1 & 5.1 \\
\hline Parity & 2.6 & 1.8 & 2.9 & 1.8 \\
\hline Recent alcohol, g/day & 6.5 & 11.7 & 5.8 & 10.0 \\
\hline \multirow[t]{2}{*}{ Cumulative average alcohol, g/day } & 6.4 & 9.5 & 5.5 & 8.2 \\
\hline & $\mathrm{N}$ & $\%$ & $\mathrm{~N}$ & $\%$ \\
\hline First-degree family history & 79 & 16.8 & 16 & 12.6 \\
\hline \multicolumn{5}{|l|}{ Year of diagnosis } \\
\hline 19901999 & 251 & 53.3 & 91 & 71.7 \\
\hline $2000-2004$ & 182 & 38.6 & 26 & 20.5 \\
\hline $2005 \quad 2009$ & 38 & 8.1 & 10 & 7.9 \\
\hline \multicolumn{5}{|l|}{ Tumor size } \\
\hline $0.1 \quad 2.0 \mathrm{~cm}$ & 365 & 77.5 & 68 & 53.5 \\
\hline $2.1 \quad 4.0 \mathrm{~cm}$ & 75 & 15.9 & 46 & 36.2 \\
\hline$>4.0 \mathrm{~cm}$ & 23 & 4.9 & 7 & 5.5 \\
\hline Unknown & 8 & 1.7 & 6 & 4.7 \\
\hline \multicolumn{5}{|l|}{ Lymph node involvement } \\
\hline None & 349 & 74.1 & 95 & 74.8 \\
\hline 13 positive nodes & 85 & 18.0 & 22 & 17.3 \\
\hline$>3$ positive nodes & 33 & 7.0 & 8 & 6.3 \\
\hline Metastatic at diagnosis & 4 & 0.8 & 1 & 0.8 \\
\hline Unknown & 0 & 0 & 1 & 0.8 \\
\hline \multicolumn{5}{|l|}{ Grade } \\
\hline Well-differentiated & 124 & 26.3 & 6 & 4.7 \\
\hline Moderately differentiated & 243 & 51.6 & 35 & 27.6 \\
\hline Poorly differentiated & 89 & 18.9 & 67 & 52.8 \\
\hline Unknown & 15 & 3.2 & 19 & 15.0 \\
\hline \multicolumn{5}{|l|}{ Stage ${ }^{a}$} \\
\hline I & 305 & 64.8 & 57 & 44.9 \\
\hline$\|$ & 122 & 25.9 & 59 & 46.5 \\
\hline III & 40 & 8.5 & 9 & 7.1 \\
\hline IV & 4 & 0.8 & 1 & 0.8 \\
\hline Unknown & 0 & 0 & 1 & 0.8 \\
\hline
\end{tabular}

ER estrogen receptor, NHS Nurses' Health Study, BMI body mass index

${ }^{\text {a }}$ Staging was based on tumor size and lymph node involvement

In the single-probe analysis, after adjusting for multiple comparisons, no probes were significantly differentially expressed by recent alcohol consumption (i.e. $10+$ vs. $0 \mathrm{~g} /$ day) in tumor or tumor-adjacent normal samples (Additional file 2: Table S3 and Additional file 3: Figure S2). When comparing alcohol intake $<10$ vs. 0 g/day, two probes showed significantly decreased expression in ER- tumors only (FDR $=0.05$, Additional file 2: Table S3); however, no such significantly decreased expression was observed when comparing alcohol intake of $10+$ vs. $0 \mathrm{~g} /$ day.

In contrast to the single-probe analysis, we observed significant enrichment for 239 pathway-defined gene sets (FDR $<0.25)$ among ER+ tumors when comparing recent alcohol intake of $10+\mathrm{g} /$ day with $0 \mathrm{~g} /$ day, including 220 upregulated and 19 downregulated gene sets (Fig. 2). Out of the 220 upregulated gene sets, $63(28.6 \%)$ were replicated in TCGA, of which 28 were at FDR $<0.1$ (Table 3 and Additional file 2: Table S4); out of the 19 downregulated gene sets, 11(57.9\%) were replicated, of which 5 were at FDR $<0.1$ (Table 3). Among the replicated and significantly enriched (FDR <0.1) gene sets in ER+ tumors, alcohol intake (i.e. $10+$ vs. $0 \mathrm{~g} /$ day) was associated with overexpression of genes involved in RNA metabolism and transport (e.g. REACTOME_METABOLISM_OF_RNA), cell cycle (e.g. GO_MEIOTIC_CELL_CYCLE), DNA repair (e.g. REACTOME_DOUBLE_STRAND_BREAK_REPAIR), downregulation of lipid metabolism (i.e. REACTOME_LIPID_DIGESTION_MOBILIZATION_AND_TRANSPORT) and PPAR signaling pathway (i.e. KEGG_PPAR_SIGNALING_PATHWAY). As there were multiple pathwaydefined gene sets linking to similar biological processes, we noted that these gene sets contained both common and distinct genes. For instance, the leading-edge subset analysis revealed that among the three DNA repair related gene sets, there were six common genes (i.e. ATM, LIG1, NBN, RAD50, RAD52 and RPA1) which accounted for $12 \%, 43 \%$ and $10 \%$ of the key genes (i.e. leading-edge subsets) in the gene set GO_DNA_REPAIR, REACTOME_DOUBLE_STRAND_BREAK_REPAIR and GO_RESPONSE_TO_DNA_DAMAGE_STIMULUS, respectively. In contrast to ER + tumors, among ER+ tumor-adjacent normal specimens, there was no enrichment for cell cycle related gene sets, and several gene sets of RNA processing were significantly enriched but downregulated (Fig. 3a). However, in both ER + tumors and tumor-adjacent normal, alcohol consumption was associated with significant downregulation in lipid metabolism and in the PPAR signaling pathway. The PPAR signaling pathway consists of three subfamilies (i.e. alpha, gamma and delta) and the leading-edge subset analysis among ER+ tumors revealed that PPARG specifically was among the core genes that accounted for the enrichment signal.

For ER- tumors, we observed significant enrichment for 665 pathway-defined gene sets $(F D R<0.25)$ when comparing recent alcohol intake of $10+\mathrm{g} /$ day with $0 \mathrm{~g} /$ day, including 604 upregulated and 61 downregulated gene sets (Fig. 2). Out of the 604 upregulated gene sets, $112(18.5 \%)$ were replicated in TCGA, of which 68 were at FDR $<0.1$ (Table 4 and Additional file 2: Table S5); out of the 61 downregulated gene sets, $3(4.9 \%)$ were replicated but none were at FDR $<0.1$. The 68 reproducible and significantly (FDR <0.1) upregulated gene sets 


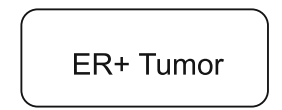

220 up and 19 down regulated gene sets at $\mathrm{FDR}<0.25$

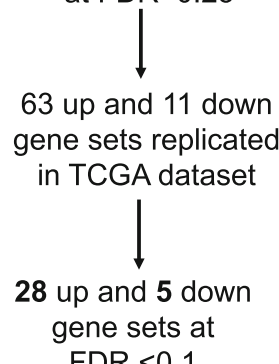

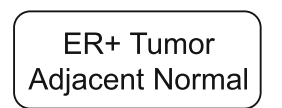

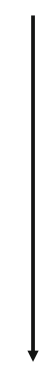

1 up and 334 down gene sets at FDR $<0.05$

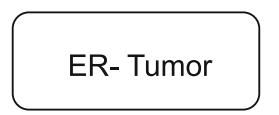

604 up and 61 down regulated gene sets at FDR $<0.25$<smiles>[13CH3][13CH3]</smiles>

112 up and 3 down gene sets replicated in TCGA dataset

68 up and 0 down gene sets at

FDR $<0.1$
ER-Tumor Adjacent Normal

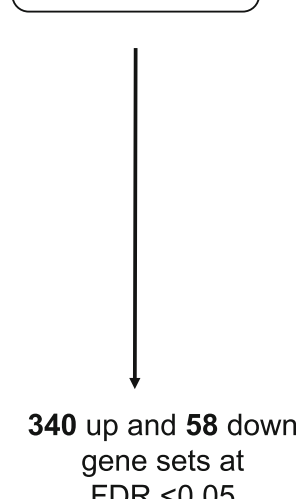

Fig. 2 Number of enriched pathway-defined gene sets by alcohol (10+ vs. 0 g/day) in the Nurses' Health Study (NHS) and the NHSII. ER estrogen receptor, FDR false discovery rate, TGCA The Cancer Genome Atlas

Table 3 Enriched gene sets ${ }^{a}$ by recent alcohol consumption ${ }^{b}$ in ER+ tumors in the NHS and the NHSII

\begin{tabular}{|c|c|c|c|}
\hline Pathway-defined gene set & Number of enriched genes & NES & FDR \\
\hline \multicolumn{4}{|l|}{ Upregulated } \\
\hline REACTOME_NONSENSE_MEDIATED_DECAY_ENHANCED_BY_THE_EXON_JUNCTION_COMPLEX & 106 & 2.56 & $<0.0001$ \\
\hline REACTOME_INFLUENZA_LIFE_CYCLE & 134 & 2.49 & $<0.0001$ \\
\hline REACTOME_METABOLISM_OF_RNA & 248 & 2.14 & 0.001 \\
\hline REACTOME_NEP_NS2_INTERACTS_WITH_THE_CELLULAR_EXPORT_MACHINERY & 26 & 1.99 & 0.007 \\
\hline REACTOME_TRANSPORT_OF_MATURE_MRNA_DERIVED_FROM_AN_INTRONLESS_TRANSCRIPT & 31 & 1.98 & 0.008 \\
\hline REACTOME_TRANSPORT_OF_RIBONUCLEOPROTEINS_INTO_THE_HOST_NUCLEUS & 26 & 1.97 & 0.008 \\
\hline REACTOME_ANTIVIRAL_MECHANISM_BY_IFN_STIMULATED_GENES & 61 & 1.93 & 0.014 \\
\hline POSITIVE_REGULATION_OF_TRANSCRIPTION_FROM_RNA_POLYMERASE_II_PROMOTER & 61 & 1.93 & 0.015 \\
\hline REACTOME_INTERACTIONS_OF_VPR_WITH_HOST_CELLULAR_PROTEINS & 31 & 1.90 & 0.018 \\
\hline MRNA_PROCESSING_GO_0006397 & 67 & 1.89 & 0.019 \\
\hline REACTOME_SYNTHESIS_OF_GLYCOSYLPHOSPHATIDYLINOSITOL_GPI & 17 & 1.89 & 0.019 \\
\hline MEIOTIC_CELL_CYCLE & 24 & 1.89 & 0.020 \\
\hline REACTOME_TRANSPORT_OF_MATURE_TRANSCRIPT_TO_CYTOPLASM & 51 & 1.86 & 0.025 \\
\hline RNA_PROCESSING & 159 & 1.85 & 0.027 \\
\hline REACTOME_PROCESSING_OF_CAPPED_INTRON_CONTAINING_PRE_MRNA & 132 & 1.83 & 0.028 \\
\hline REACTOME_METABOLISM_OF_NON_CODING_RNA & 45 & 1.83 & 0.029 \\
\hline REACTOME_DOUBLE_STRAND_BREAK_REPAIR & 18 & 1.84 & 0.030 \\
\hline PROTEIN_RNA_COMPLEX_ASSEMBLY & 60 & 1.84 & 0.030 \\
\hline REACTOME_REGULATION_OF_GLUCOKINASE_BY_GLUCOKINASE_REGULATORY_PROTEIN & 26 & 1.78 & 0.048 \\
\hline \multicolumn{4}{|l|}{ Downregulated } \\
\hline REACTOME_LIPID_DIGESTION_MOBILIZATION_AND_TRANSPORT & 38 & -2.12 & 0.017 \\
\hline REACTOME_SMOOTH_MUSCLE_CONTRACTION & 21 & -2.13 & 0.024 \\
\hline REACTOME_MUSCLE_CONTRACTION & 40 & -2.06 & 0.025 \\
\hline KEGG_PPAR_SIGNALING_PATHWAY & 58 & -2.03 & 0.025 \\
\hline
\end{tabular}

ER estrogen receptor, NHS Nurses' Health Study, NES normalized enrichment score, FDR false discovery rate ${ }^{a}$ Only gene sets replicated in The Cancer Genome Atlas (TCGA) dataset and FDR $<0.05$ are shown

${ }^{\mathrm{b}}$ Enriched gene sets for comparison of recent alcohol consumption $10+\mathrm{vs} .0 \mathrm{~g} / \mathrm{day}$ 

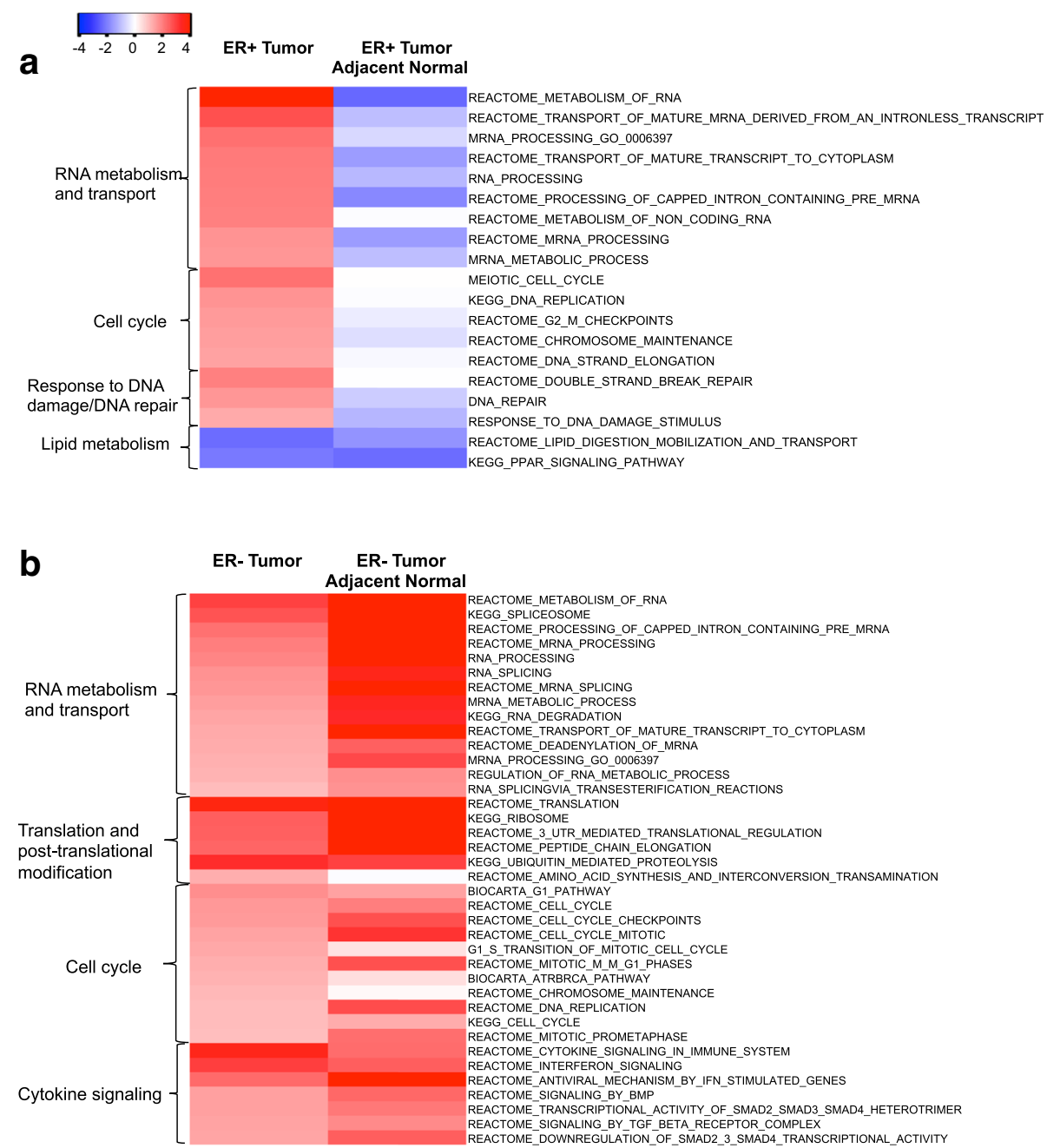

Fig. 3 a, b Replicated enriched pathway-defined gene sets (false discovery rate (FDR) $<0.1$ ) by alcohol consumption in the Nurses' Health Study (NHS) and the NHSII. Replicated significantly enriched gene sets according to recent alcohol intake (i.e. $10+\mathrm{vs} .0 \mathrm{~g} /$ day) in estrogen receptor $(E R)+$ tumors and the same gene sets in tumor-adjacent normal tissues (a), and in ER-tumors and the same gene sets in tumor-adjacent normal tissues (b), NHSI/II. The primary biological processes observed are shown: N=19 and 38 gene sets for ER+ and ER- tumors, respectively;

$-\log 10(\mathrm{FDR})^{*}$ direction: red indicates upregulation and blue downregulation

identified among ER- tumors demonstrated that, in addition to the upregulation in RNA processing and cell cycle regulation, alcohol intake was also linked to strong enrichment in cytokine signaling (e.g. REACTOME_INTERFERON_SIGNALING and REACTOME_SIGNALING_BY_TGF_BETA_RECEPTOR_COMPLEX) and translation and post-translational modification (e.g. KEGG_UBIQUITIN_MEDIATED_PROTEOLYSIS). Among the cytokine signaling pathways, four gene sets were related to TGF- $\beta /$ SMAD/BMP signaling; four common genes (i.e., SMAD4, SMURF2, UBE2D3, and UBE2D1) were observed among the leading-edge subsets of these four gene sets, and the overlapping genes accounted for about $15 \%, 50 \%, 21 \%$ and $29 \%$ of the leading-edge subset of REACTOME_SIGNALING_BY_TGF_BETA_RECEPTOR_COMPLEX, REACTOME_DOWNREGULATION_
OF_SMAD2_3_SMAD4_TRANSCRIPTIONAL_ACTIVITY, and REACTOME_TRANSCRIPTIONAL_ACTIVITY_OF_SMAD2_SMAD3_SMAD4_HETEROTRIMER, and REACTOME_SIGNALING_BY_BMP, respectively. Similar significant enrichment was also observed among ER- tumor-adjacent normal tissues (Fig. 3b).

In both ER+ and ER- tumors, alcohol intake was associated with upregulation in gene sets involved in RNA metabolism and transport and cell cycle. For instance, "REACTOME_METABOLISM_OF_RNA" was the top ranked pathway under the category of RNA metabolism and transport in both ER+ and ER- tumors (Fig. 3a and b). However, despite some overlapping gene sets within each category, there were some specific gene sets in either ER+ or ER- tumors. For example, among cell cycle related gene sets, in ER+ tumors, genes involved in the 
Table 4 Enriched gene sets ${ }^{a}$ by recent alcohol consumption ${ }^{b}$ in ER- tumors in the NHS and the NHSII

\begin{tabular}{|c|c|c|c|}
\hline Pathway-defined gene set & Number of enriched genes & NES & FDR \\
\hline \multicolumn{4}{|l|}{ Upregulated } \\
\hline REACTOME_TRANSLATION & 144 & 2.31 & 0.0002 \\
\hline REACTOME_CYTOKINE_SIGNALING_IN_IMMUNE_SYSTEM & 218 & 2.32 & 0.0003 \\
\hline KEGG_UBIQUITIN_MEDIATED_PROTEOLYSIS & 124 & 2.38 & 0.001 \\
\hline REACTOME_METABOLISM_OF_MRNA & 206 & 2.25 & 0.001 \\
\hline PROTEIN_RNA_COMPLEX_ASSEMBLY & 60 & 2.25 & 0.001 \\
\hline REACTOME_INTERFERON_SIGNALING & 129 & 2.21 & 0.001 \\
\hline REACTOME_METABOLISM_OF_RNA & 248 & 2.18 & 0.001 \\
\hline REACTOME_SRP_DEPENDENT_COTRANSLATIONAL_PROTEIN_TARGETING_TO_MEMBRANE & 108 & 2.17 & 0.001 \\
\hline REACTOME_INFLUENZA_LIFE_CYCLE & 134 & 2.13 & 0.002 \\
\hline KEGG_SPLICEOSOME & 122 & 2.10 & 0.002 \\
\hline KEGG_RIBOSOME & 84 & 2.08 & 0.003 \\
\hline BIOCARTA_CDC42RAC_PATHWAY & 15 & 2.08 & 0.003 \\
\hline REACTOME_3_UTR_MEDIATED_TRANSLATIONAL_REGULATION & 104 & 2.07 & 0.003 \\
\hline REACTOME_NONSENSE_MEDIATED_DECAY_ENHANCED_BY_THE_EXON_JUNCTION_COMPLEX & 106 & 2.05 & 0.003 \\
\hline REACTOME_PEPTIDE_CHAIN_ELONGATION & 85 & 2.03 & 0.004 \\
\hline REACTOME_ANTIVIRAL_MECHANISM_BY_IFN_STIMULATED_GENES & 61 & 2.01 & 0.005 \\
\hline RIBONUCLEOPROTEIN_COMPLEX_BIOGENESIS_AND_ASSEMBLY & 79 & 1.97 & 0.006 \\
\hline REACTOME_PROCESSING_OF_CAPPED_INTRON_CONTAINING_PRE_MRNA & 132 & 1.97 & 0.006 \\
\hline REACTOME_INFLUENZA_VIRAL_RNA_TRANSCRIPTION_AND_REPLICATION & 101 & 1.94 & 0.008 \\
\hline REACTOME_MRNA_PROCESSING & 151 & 1.92 & 0.009 \\
\hline RNA_PROCESSING & 159 & 1.88 & 0.013 \\
\hline BIOCARTA_G1_PATHWAY & 25 & 1.84 & 0.017 \\
\hline RNA_SPLICING & 87 & 1.82 & 0.020 \\
\hline REACTOME_MRNA_SPLICING & 104 & 1.80 & 0.023 \\
\hline REACTOME_CELL_CYCLE & 328 & 1.79 & 0.024 \\
\hline REACTOME_CELL_CYCLE_CHECKPOINTS & 97 & 1.78 & 0.026 \\
\hline CELLULAR_COMPONENT_ASSEMBLY & 272 & 1.75 & 0.030 \\
\hline REGULATION_OF_TRANSCRIPTION_FROM_RNA_POLYMERASE_II_PROMOTER & 271 & 1.75 & 0.030 \\
\hline MRNA_METABOLIC_PROCESS & 78 & 1.74 & 0.031 \\
\hline REACTOME_HIV_INFECTION & 183 & 1.74 & 0.031 \\
\hline RANSCRIPTION_FROM_RNA_POLYMERASE_II_PROMOTER & 427 & 1.73 & 0.032 \\
\hline REACTOME_SIGNALING_BY_BMP & 21 & 1.72 & 0.032 \\
\hline REACTOME_TRANSCRIPTIONAL_ACTIVITY_OF_SMAD2_SMAD3_SMAD4_HETEROTRIMER & 33 & 1.72 & 0.033 \\
\hline $\begin{array}{l}\text { REACTOME_ACTIVATION_OF_THE_MRNA_UPON_BINDING_OF_THE_CAP_BINDING_ } \\
\text { COMPLEX_AND_EIFS_AND_SUBSEQUEN__BINDING_TO_43S }\end{array}$ & 56 & 1.71 & 0.034 \\
\hline REACTOME_SIGNALING_BY_TGF_BETA_RECEPTOR_COMPLEX & 56 & 1.70 & 0.037 \\
\hline REACTOME_CELL_CYCLE_MITOTIC & 255 & 1.70 & 0.037 \\
\hline NUCLEAR_EXPORT & 31 & 1.68 & 0.041 \\
\hline REACTOME_DOWNREGULATION_OF_SMAD2_3_SMAD4_TRANSCRIPTIONAL_ACTIVITY & 18 & 1.68 & 0.041 \\
\hline POSITIVE_REGULATION_OF_NUCLEOBASENUCLEOSIDENUCLEOTIDE_AND_NUCLEIC_ACID_METABOLIC_PROCESS & 143 & 1.68 & 0.042 \\
\hline KEGG_RNA_DEGRADATION & 55 & 1.67 & 0.042 \\
\hline KEGG_ADHERENS_JUNCTION & 70 & 1.67 & 0.043 \\
\hline G1_S_TRANSITION_OF_MITOTIC_CELL_CYCLE & 25 & 1.67 & 0.045 \\
\hline REACTOME_TRANSPORT_OF_MATURE_TRANSCRIPT_TO_CYTOPLASM & 51 & 1.66 & 0.045 \\
\hline POSITIVE_REGULATION_OF_TRANSCRIPTION & 134 & 1.65 & 0.048 \\
\hline \multicolumn{4}{|l|}{ Downregulated } \\
\hline None & & & \\
\hline
\end{tabular}

ER estrogen receptor, NHS Nurses' Health Study, NES normalized enrichment score, FDR false discovery rate

a Only gene sets replicated in The Cancer Genome Atlas (TCGA) dataset and FDR $<0.05$ are shown

${ }^{b}$ Enriched gene sets for comparison of recent alcohol consumption $10+\mathrm{vs} .0 \mathrm{~g} / \mathrm{day}$ 
G2/M phase checkpoint were overexpressed while in ER- tumors, genes involved in the G1 or G1/S transition were upregulated (Fig. 3a and b). Further, as we hypothesized that the biological mechanism of the alcohol and breast cancer association may vary between ER+ and ER- tumors, we also noted that there were several ER+ or ER- tumor-specific gene sets. Among ER+ tumors, alcohol intake was linked to gene sets involved in upregulation of DNA repair but this not observed among ERtumors. In addition, genes related to lipid metabolism were down-expressed in ER+ tumors but not in ER- tumors. On the other hand, upregulation in cytokine signaling was only observed among ER- tumors.

Among ER+ tumor-adjacent normal tissues, we observed significant enrichment for 335 pathway-defined gene sets (FDR $<0.05)$, of which 1 was upregulated and 334 were downregulated by recent alcohol intake (i.e. 10 + vs. 0 g/day); among ER- tumor-adjacent normal tissues, 340 and 58 pathway-defined gene sets were significantly (FDR <0.05) upregulated and downregulated, respectively. Table 5 presents the top 10 ranked upregulated or downregulated pathway-defined gene sets identified in the NHS/NHSII. Among ER+ tumor-adjacent normal tissues, only one gene set (i.e. olfactory transduction) was significantly upregulated at FDR $<0.05$; the top ranked downregulated gene sets included mitochondrial respiratory electron transport and TCA cycle, WNT signaling pathway, integrin pathway and focal adhesion, and fatty acids/triacylglycerol/ketone body metabolism. Among ER- tumor-adjacent normal tissues, the top ranked upregulated gene sets, such as RNA metabolism and translation, were also seen among those top ranked in ER- tumors; the strongest enrichment for downregulated gene sets included neuroactive ligand-receptor interaction, GPCR ligand binding, and cytochrome P450 arranged by substrate type.

As several enzymes, such as alcohol dehydrogenase $(\mathrm{ADH})$ and aldehyde dehydrogenase (ALDH), are known to play an important role in alcohol metabolism, we specifically examined the expression of genes involved in alcohol metabolism in tumors and adjacent normal tissues. Most of these genes, including $A D H 1 B, A L D H 1 A 1, A D H 1 C$ and $A L D H 2$, were significantly down-expressed in ER+ or ERtumors compared to tumor-adjacent normal tissues (Table 6), although none showed significant differential expression by alcohol intake in either tissue type. For instance, among the seven alcohol metabolism genes included in our data, $A D H 1 B$ showed the most reduced expression in ER+ or ER- tumors (fold change 0.40).

As more than half (i.e. 60\%) of the tumors in the NHS/ NHSII were stage I tumors while the majority of the tumors in TCGA were stage II or III, we further conducted stratified analyses according to tumor stage in secondary analyses. Specifically, we performed GSEA among stage
II/III ER+ tumors in the NHS/NHSII and further validated in stage II/III ER+ tumors in TCGA; we were not able to conduct similar analysis among stage II/III ER- tumors because of the limited case numbers in TCGA. We found that the replicated enrichment signals in stage II/III ER+ tumors were very similar to those in all ER+ tumors in the NHS/NHSII (Additional file 2: Table S6).

\section{Discussion}

To our knowledge, this is the first epidemiologic study to assess the association between pre-diagnostic alcohol consumption and breast tumor genome-wide gene expression. In the differential gene expression analysis by recent alcohol consumption, we did not find individual genes significantly upregulated or downregulated by alcohol after accounting for multiple comparisons. However, gene set analysis identified reproducible enriched pathway-defined gene sets in breast tumors. Specifically, recent alcohol intake of at least $10 \mathrm{~g} /$ day was linked to increased proliferation and lower lipid metabolism in ER + tumors; among ER- tumors, in addition to an increase in proliferation, some further signals, including upregulation in cytokine signaling, such as interferon (IFN) and TGF- $\beta$ signaling pathways, were noted.

Cohort studies generally support a stronger positive association among ER+ tumors than among ER- tumors $[26,27]$. A strong enrichment signal observed from GSEA was increased proliferation in ER+ tumors. Several of the significantly upregulated gene sets, including cell cycle regulation (e.g. mitosis and G2/M checkpoint) and DNA repair are closely related to proliferation [28]. In addition, RNA processing (e.g. RNA splicing or transport) has been shown to affect cell cycle and proliferation [29], although increased RNA processing also may be a consequence of proliferation. Our finding is consistent with experimental studies in which ethanol promoted proliferation in ER+ breast tumor cell lines [30-32]. In ER+ tumors, we also observed downregulation of lipid metabolism, including the PPAR-gamma signaling pathway. PPAR-gamma signaling plays an essential role in adipocyte differentiation and expression of adipocyte specific genes, and also regulates lipid metabolism, cell proliferation and differentiation, glucose homeostasis and inflammation [33]. Further, in experimental studies, PPAR-gamma inhibited proliferation in ER+ breast cancer cell lines [34] and ethanol inhibited PPARgamma dependent transcriptional activation [35]. Taken together, downregulation of the PPAR-gamma signaling pathway is consistent with the observed increase in proliferation in our data. In addition, lower lipid metabolism was observed among ER+ tumor-adjacent normal tissues in the current dataset. If replicated, this finding suggests that alcohol consumption disrupts lipid metabolism, providing another possible link to alcohol-related breast pathogenesis. 
Table 5 Top 10 enriched gene sets ${ }^{a}$ by alcohol consumption ${ }^{b}$ in tumor-adjacent normal samples in the NHS and the NHSII

\begin{tabular}{|c|c|c|c|}
\hline Pathway-defined gene set & Number of enriched genes & NES & FDR \\
\hline \multicolumn{4}{|l|}{ ER+ tumor-adjacent normal tissues } \\
\hline \multicolumn{4}{|l|}{ Upregulated } \\
\hline KEGG_OLFACTORY_TRANSDUCTION & 153 & 1.97 & 0.04 \\
\hline \multicolumn{4}{|l|}{ Downregulated } \\
\hline REACTOME_TCA_CYCLE_AND_RESPIRATORY_ELECTRON_TRANSPORT & 123 & -2.33 & $<0.001$ \\
\hline REACTOME_SIGNALING_BY_WNT & 60 & -2.33 & $<0.001$ \\
\hline REACTOME_PYRUVATE_METABOLISM_AND_CITRIC_ACID_TCA_CYCLE & 39 & -2.30 & $<0.001$ \\
\hline REACTOME_CTNNB1_PHOSPHORYLATION_CASCADE & 15 & -2.28 & $<0.001$ \\
\hline KEGG_FOCAL_ADHESION & 186 & -2.27 & $<0.001$ \\
\hline BIOCARTA_RHO_PATHWAY & 30 & -2.27 & $<0.001$ \\
\hline BIOCARTA_INTEGRIN_PATHWAY & 36 & -2.26 & $<0.001$ \\
\hline BIOCARTA_PYK2_PATHWAY & 27 & -2.26 & $<0.001$ \\
\hline KEGG_PATHOGENIC_ESCHERICHIA_COLI_INFECTION & 51 & -2.25 & $<0.001$ \\
\hline REACTOME_FATTY_ACID_TRIACYLGLYCEROL_AND_KETONE_BODY_METABOLISM & 151 & -2.24 & 1.55E-04 \\
\hline \multicolumn{4}{|l|}{ ER- tumor-adjacent normal } \\
\hline \multicolumn{4}{|l|}{ Up-regulated } \\
\hline REACTOME_METABOLISM_OF_MRNA & 206 & 2.87 & $<0.001$ \\
\hline REACTOME_METABOLISM_OF_RNA & 248 & 2.79 & $<0.001$ \\
\hline REACTOME_NONSENSE_MEDIATED_DECAY_ENHANCED_BY_THE_EXON_JUNCTION_COMPLEX & 106 & 2.66 & $<0.001$ \\
\hline REACTOME_INFLUENZA_LIFE_CYCLE & 134 & 2.65 & $<0.001$ \\
\hline REACTOME_3_UTR_MEDIATED_TRANSLATIONAL_REGULATION & 104 & 2.64 & $<0.001$ \\
\hline REACTOME_TRANSLATION & 144 & 2.63 & $<0.001$ \\
\hline REACTOME_SRP_DEPENDENT_COTRANSLATIONAL_PROTEIN_TARGETING_TO_MEMBRANE & 108 & 2.62 & $<0.001$ \\
\hline REACTOME_TRANSPORT_OF_MATURE_TRANSCRIPT_TO_CYTOPLASM & 51 & 2.61 & $<0.001$ \\
\hline REACTOME_PROCESSING_OF_CAPPED_INTRON_CONTAINING_PRE_MRNA & 132 & 2.60 & $<0.001$ \\
\hline REACTOME_MRNA_PROCESSING & 151 & 2.59 & $<0.001$ \\
\hline \multicolumn{4}{|l|}{ Down-regulated } \\
\hline KEGG_NEUROACTIVE_LIGAND_RECEPTOR_INTERACTION & 192 & -2.52 & $<0.001$ \\
\hline REACTOME_GPCR_LIGAND_BINDING & 297 & -2.49 & $<0.001$ \\
\hline $\begin{array}{l}\text { REACTOME_TRANSPORT_OF_GLUCOSE_AND_OTHER_SUGARS_BILE_SALTS_AND_ORGANIC } \\
\text { _ACIDS_METAL_IONS_AND_AMINE_COMPOUNDS }\end{array}$ & 76 & -2.36 & $<0.001$ \\
\hline REACTOME_CLASS_A1_RHODOPSIN_LIKE_RECEPTORS & 212 & -2.29 & 4.14E-04 \\
\hline REACTOME_POTASSIUM_CHANNELS & 86 & -2.30 & $5.18 \mathrm{E}-04$ \\
\hline REACTOME_CYTOCHROME_P450_ARRANGED_BY_SUBSTRATE_TYPE & 37 & -2.20 & 2.04E-03 \\
\hline GENERATION_OF_A_SIGNAL_INVOLVED_IN_CELL_CELL_SIGNALING & 27 & -2.14 & $3.22 \mathrm{E}-03$ \\
\hline REACTOME_VOLTAGE_GATED_POTASSIUM_CHANNELS & 36 & -2.14 & 3.29E-03 \\
\hline G_PROTEIN_SIGNALING_COUPLED_TO_CYCLIC_NUCLEOTIDE_SECOND_MESSENGER & 83 & -2.12 & 3.50E-03 \\
\hline REACTOME_G_ALPHA_ISSIGNALLING_EVENTS & 147 & -2.12 & 3.50E-03 \\
\hline
\end{tabular}

ER estrogen receptor, NHS Nurses' Health Study, NES normalized enrichment score, FDR false discovery rate

${ }^{a}$ Top 10 ranked gene sets at FDR $<0.05$ are shown for upregulation and downregulation, respectively

${ }^{b}$ Enriched gene sets for comparison of recent alcohol consumption $10+$ vs. 0 g/day

Among the hypothesized mechanisms through which alcohol consumption increases breast cancer risk, particularly ER+ disease, the most studied pathway is estrogen metabolism with supporting evidence from intervention studies that alcohol drinking is associated with increases in circulating estrogens $[5,6]$. In experimental studies, ER-mediated estrogen signaling can increase cell proliferation that in turn can induce genetic mutations [36, 37], while estrogen metabolites, independent of ER signaling, also can cause DNA damage 
Table 6 Differential expression of alcohol metabolism genes in tumor and tumor-adjacent normal tissues in the NHS and the NHSII

\begin{tabular}{|c|c|c|c|c|c|c|c|c|}
\hline \multirow[b]{2}{*}{ Probeset ID } & \multirow[b]{2}{*}{ Entrez ID } & \multirow[b]{2}{*}{ Symbol } & \multicolumn{3}{|c|}{ ER+ tumors vs. tumor-adjacent normal tissues } & \multicolumn{3}{|c|}{ ER- tumors vs. tumor-adjacent normal tissues } \\
\hline & & & $\log 2(\mathrm{FC})$ & $t$ value $^{a}$ & $\mathrm{FDR}^{\mathrm{b}}$ & $\log 2(\mathrm{FC})$ & $t$ value $^{a}$ & $\mathrm{FDR}^{\mathrm{b}}$ \\
\hline TC0401141 & 125 & $A D H 1 B$ & -1.33 & -21.1 & $2.92 \mathrm{E}-61$ & -1.32 & -11.0 & $1.59 \mathrm{E}-14$ \\
\hline TC0901044 & 216 & ALDH1A1 & -0.61 & -16.7 & $2.77 \mathrm{E}-44$ & -0.58 & -8.6 & $6.93 \mathrm{E}-11$ \\
\hline TC0401142 & 126 & ADH1C & -0.25 & -14.6 & $3.80 \mathrm{E}-36$ & -0.29 & -7.6 & $3.08 \mathrm{E}-09$ \\
\hline TC1100272 & 847 & CAT & -0.34 & -10.2 & $1.99 \mathrm{E}-20$ & -0.32 & -4.2 & $6.20 \mathrm{E}-04$ \\
\hline TC1200702 & 217 & $A L D H 2$ & -0.18 & -7.0 & $6.53 \mathrm{E}-11$ & -0.20 & -4.0 & 1.01E-03 \\
\hline TC0401137 & 128 & ADH5 & -0.11 & -4.8 & 7.69E-06 & -0.04 & -0.7 & $6.00 \mathrm{E}-01$ \\
\hline TC1000709 & 1571 & CYP2E1 & -0.02 & -1.9 & $8.21 \mathrm{E}-02$ & -0.02 & -0.6 & 7.02E-01 \\
\hline
\end{tabular}

ER estrogen receptor, NHS Nurses' Health Study, FDR false discovery rate, FC fold change

${ }^{a}$ The $t$ values were obtained from paired $t$ tests of tumor and adjacent normal tissues: 357 pairs of ER+ tumor and ER+ tumor-adjacent normal tissues, and 86 pairs for ER- tumor and ER- tumor-adjacent normal, respectively

${ }^{b}$ FDR was calculated across all the 25,979 probes

[37]. Although our data are consistent with estrogen/ER signaling mediated increased proliferation and DNA damage, we did not find alcohol intake to be associated with increased expression of specific estrogen-related genes or gene sets in ER+ tumors or tumor-adjacent normal tissue. The reason is unclear. To what extent alcohol-associated estrogen metabolism occurs in breast tissue in cancer-free women and whether it would be preserved in breast tissue during tumor progression is not known. In a recent study that explored parityassociated gene expression signatures, the signature identified in normal breast tissue was preserved in ER+ but not in ER- breast tumors [13]. Further, as shown in alcohol intervention studies with a crossover study design $[5,6]$, the alcohol-associated increases in circulating estrogen or estrogen metabolite levels are a relatively acute alcohol effect. Whether alcohol-induced estrogen metabolism occurring in breast tissue is similarly short term or more long lasting is not known, and could have influenced our ability to detect an association.

Among ER- tumors, recent alcohol consumption was also linked to increases in proliferation. In addition to cell cycle upregulation, significant increases in translational and post-translational modification were observed, which may be associated with alterations in cell cycle and regulation of cell growth [38]. However, a prior experimental study reported that ethanol only induced proliferation in ER+ but not ER- breast cancer cell lines [31]. The observation of alcohol-related proliferation in both ER+ and ER- tumors in our data suggests that alcohol-induced proliferation may not exclusively act through estrogen metabolism, as no pathway-defined gene sets related to estrogen metabolism were significantly enriched by alcohol intake.

Compared to the enrichment signals observed among ER + tumors, a distinct enrichment was found in ER- tumors: alcohol intake was associated with upregulation in cytokine signaling including IFN signaling and TGF- $\beta$ signaling pathways. Alcohol is known to modulate the immune system in a complex way. In animal models, chronic ethanol exposure was shown to alter cytokine levels (e.g. TNF- $\alpha$, TGF- $\beta$, IL-6) in a variety of tissues, including lung, liver and brain [39], although breast tissue was not assessed. In a population study of over 1300 women, circulating IL-6 levels significantly increased among women consuming at least one alcoholic drink per day, while no increase was reported among women with light alcohol intake (i.e. less than one drink/day) [40]. In addition, cytokines play an important role in breast tumor growth and progression [41, 42]. Expression levels of multiple cytokines were higher in ER- compared to ER+ breast tumors, including IFN- $\gamma$, TNF- $\alpha$, and IL- 6 and IL-8 [43]. Further, breast tumor ER expression may be an important mediator of the transition of TGF- $\beta$ from tumor suppression to tumor promotion: loss of ER expression (i.e. in ER- tumor cells) and loss of hormonally controlled growth may lead to an increased tumor promoting effect of TGF- $\beta$ [44]. Interestingly, the significantly enriched pathway-defined gene sets identified in ER- tumors had a consistent enrichment pattern and even stronger enrichment signals among ER- tumor-adjacent normal tissues, while no similarities were observed in enrichment signals between ER+ tumors and ER+ tumor-adjacent normal tissues. One possible reason is that ER- tumors in this dataset were on average more advanced than ER+ tumors (i.e. larger in size, higher in grade and at a more advanced stage); thus, although the tumor-adjacent normal tissues were defined as generally $>1 \mathrm{~cm}$ from the tumor edge, ER- tumors may have more strongly influenced adjacent normal tissues. However, the fact that adjacent normal tissues may contain information on the environment surrounding the tumors may not directly relate to alcohol consumption; thus, the exact reason for the consistent enrichment pattern in ER- tumors and adjacent normal tissues is not clear. As this is the first ever assessment of alcohol intake and gene expression in both tumor and adjacent normal tissues, replication of this finding in other studies will be important. 
Although none of the known alcohol metabolism genes were differentially expressed by alcohol intake in breast tumors in this study, several of these genes, including $A D H 1 B, A D H 1 C, A L D H 2$ and $A L D H 1 A 1$ were substantially downregulated in tumors compared to tumor-adjacent normal tissues, regardless of tumor ER expression. Our results are consistent with a previous study that observed class I ADH (including $A D H 1 A$, $A D H 1 B$ and $A D H 1 C$ ) to be more highly expressed, at both mRNA and protein levels, in normal breast tissues from cancer-free women than in invasive breast tumor tissues [45]. Despite no significant enrichment of pathway-defined gene sets involved in alcohol metabolism according to alcohol intake, it was interesting to see that recent alcohol consumption (i.e. $10+$ g/day) was marginally associated with significant downregulation in retinol metabolism (i.e. KEGG_RETINOL_METABOLISM) among ER+ tumors (FDR $=0.11$; also replicated in TCGA) because ADH enzymes are also involved in retinol metabolism [46]. Abnormal retinoid metabolism has been observed in several cancers, including breast cancer [47].

Our study, using tumor genome-wide gene expression profiling provided novel insights of alcohol-related molecular pathways in breast tumors. The evaluation was conducted within large prospective cohort studies with detailed data on alcohol consumption, covariates, and cancer diagnosis and tumor characteristics. In addition, this study has a sizable number of breast tumor and tumor-adjacent normal specimens. Further, our results, using microarrays, were validated in another platform using RNA-Seq. Finally, in addition to single-probe analysis, we conducted pathway analysis (i.e. GSEA), which has several advantages over single-gene analysis. For example, it makes interpretation easier by focusing on pathways and biological processes rather than single high-scoring genes which may be poorly annotated. GSEA also makes it possible to detect modest expression changes in individual genes as it can increase the signalto-noise ratio. However, one drawback in this GSEA is that the $P$ value estimation using gene permutation under GSEA "Preranked" function does not take into account correlation among genes [48].

Our study also has limitations. One limitation is the use of FFPE tissues for gene expression profiling, because FFPE can make retrieval of RNA challenging due to chemical modification of RNA and related RNA degradation. However, archived FFPE samples have been shown comparable to fresh-frozen samples in assessing differential expression in lung, colon and kidney tissues [49]. In addition, our results were validated in a dataset derived from fresh-frozen breast tumor samples that were part of TCGA. However, there were differences in patient characteristics (e.g. age) and tumor characteristics (i.e. tumor stage) between the NHS and TCGA datasets. Another limitation is the lack of a validation dataset for tumoradjacent normal tissues. Further, women participating in this study had relatively low levels of alcohol consumption and thus we were not able to evaluate the effect of moderate to heavy alcohol intake on tumor gene expression. Indeed, in epidemiologic studies, compared to women without recent alcohol intake, those with recent consumption $10-20$ g/day had only 10\% increased breast cancer risk while those consuming at least $30 \mathrm{~g} /$ day had $>30 \%$ increased risk [3]. Finally, the tumor gene expression profiling here may be a mixed profiling of malignant epithelial and stromal cells. Laser capture microdissection can be used to isolate specific cell types; however, it was not feasible considering the large sample size in this study.

\section{Conclusions}

Our data suggest that alcohol consumption is associated with increased proliferation and lower lipid metabolism among ER+ breast tumors while among ER- breast tumors, alcohol consumption is not only linked to increased proliferation but also upregulation in cytokine signaling, particularly IFN and TGF- $\beta$ signaling. Future studies of gene expression profiling in normal breast tissues from cancerfree women are of particular interest. Alcohol consumption is not considered a prognostic factor for breast cancer recurrence or death [50]. Assessment of the effect of alcohol consumption on normal breast tissues, together with profiling data from breast tumors and/or tumor-adjacent normal tissues will be critical in further elucidating the alcoholrelated breast carcinogenesis. Furthermore, as alcohol is known to impact one-carbon metabolism and induce aberrant DNA methylation [51], integrating DNA methylation and gene expression data may provide deeper insights into the underlying biology of the association between alcohol and breast cancer.

\section{Additional files}

\footnotetext{
Additional file 1: Figure S1. ESR1, PGR, ERBB2 mRNA expression by $\mathrm{HC}$ $E R$, PR, and HER2, respectively, in the NHS and the NHSII. (PDF $273 \mathrm{~kb}$ )

Additional file 2: Table S1. Comparison of study population characteristics in the NHS/NHSII and TCGA. Table S2. Characteristics of invasive breast cancer cases by recent alcohol consumption in the TCGA. Table S3. Top 10 ranked differentially expressed probes by recent alcohol consumption in the NHS and the NHSII. Table S4. Enriched gene sets (FDR 0.05-0.1) by recent alcohol consumption in ER+ tumors in the $\mathrm{NHS}$ and the NHSII. Table S5. Enriched gene sets (FDR 0.05-0.1) by recent alcohol consumption in ER- tumors in the NHS and the NHSII. Table S6. Enriched gene sets by alcohol consumption in stage II/II ER+ tumors in the NHS and the NHSII. (DOCX 56 kb)

Additional file 3: Figure S2. Differentially expressed probes $(\mathrm{N}=25,979)$ by alcohol consumption in the NHS and the NHSII. The top four figures show recent alcohol intake $>0-<10$ vs. $0 \mathrm{~g} /$ day and the bottom four figures show recent alcohol intake $10+v s .0 \mathrm{~g} /$ day. (PDF $1418 \mathrm{~kb})$
} 


\section{Abbreviations}

ADH: Alcohol dehydrogenase; ALDH: Aldehyde dehydrogenase; AUC: Area under the curve; BMI: Body mass index; CGEMS: Cancer Genetic Markers of Susceptibility; Cl: Confidence interval; ER: Estrogen receptor; FDR: False discovery rate; FFPE: Formalin-fixed paraffin-embedded; GO: Gene Ontology; GSEA: Gene set enrichment analysis; HER2: Human epidermal growth factor receptor 2; IFN: Interferon; IHC: Immunohistochemistry; IL: Interleukin; KEGG: Kyoto Encyclopedia of Genes and Genomes; LIMMA: Linear models for microarray data; MHT: Menopausal hormone therapy; MSigDB: Molecular Signatures Database; NES: Normalized enrichment score; NHS: Nurses' Health Study; PR: Progesterone receptor; RMA: Robust multiarray average; RNASeq: RNA sequencing; RSEM: RNA-Seq by expectation maximization; TCGA: The Cancer Genome Atlas; TGF: Transforming growth factor; TNF: Tumor necrosis factor

\section{Acknowledgements}

We would like to thank the participants and staff of the Nurses' Health Study and the Nurses' Health Study II for their valuable contributions and the cancer registries in the following states for their help: $A L, A Z, A R, C A, C O, C T$, $\mathrm{DE}, \mathrm{FL}, \mathrm{GA}, \mathrm{ID}, \mathrm{IL}, \mathrm{IN}, \mathrm{IA}, \mathrm{KY}, \mathrm{LA}, \mathrm{ME}, \mathrm{MD}, \mathrm{MA}, \mathrm{Ml}, \mathrm{NE}, \mathrm{NH}, \mathrm{NJ}, \mathrm{NY}, \mathrm{NC}, \mathrm{ND}, \mathrm{OH}$, OK, OR, PA, RI, SC, TN, TX, VA, WA and WY. The authors assume full responsibility for analyses and interpretation of these data.

\section{Funding}

This study was supported in part by a Komen Foundation Grant SAC110014 and the NIH NCI U19/GAME-ON DRIVE (CA148065) initiative, UM1 CA186107. P01 CA87969, and UM1 CA176726.

\section{Availability of data and materials}

Gene expression data are publicly available through the Gene Expression Omnibus [GEO:GSE93601].

\section{Authors' contributions}

Conception and design: SEH; development of methodology: JW, YJH, $\mathrm{AH}$, VJC, AHB and SEH; acquisition of data: DJH, SEH, CBA, TAK, FM and CMV; analysis and interpretation of data (e.g., statistical analysis, biostatistics, computational analysis): JW, YJH, SEH and AHB; writing, review and/or revision of the manuscript: JW, YJH, AHE, RMT, AH, VJC, CBA, VPA, AB, FJC, TAK, FM, CMV, DJH, AHB and SEH; administrative, technical, or material support: DJH and SEH; study supervision: SEH and AHB. All authors read and approved the final manuscript.

\section{Ethics approval and consent to participate}

The study was approved by the Committee on the Use of Human Subjects in Research at the Brigham and Women's Hospital. Informed consent was obtained from participating women.

\section{Competing interests}

The authors declare that they have no competing interests.

\section{Consent for publication}

Not applicable.

\section{Publisher's Note}

Springer Nature remains neutral with regard to jurisdictional claims in published maps and institutional affiliations.

\section{Author details}

Department of Biostatistics and Epidemiology, School of Public Health and Health Sciences, University of Massachusetts Amherst, 715 N Pleasant Street, Amherst, MA 01003, USA. ${ }^{2}$ Present address: Department of Preventive Medicine, University of Southern California, Harlyne J. Norris Research Tower, 1450 Biggy Street, Los Angeles, CA 90033, USA. Department of Pathology, Beth Israel Deaconess Medical Center and Harvard Medical School, Boston, MA 02215, USA. ${ }^{4}$ Channing Division of Network Medicine, Department of Medicine, Brigham and Women's Hospital and Harvard Medical School, 181 Longwood Avenue, Boston, MA 02115, USA. ${ }^{5}$ Department of Epidemiology, Harvard T.H. Chan School of Public Health, 677 Huntington Avenue, Boston, MA 02115, USA. 'Division of Preventive Medicine, Department of Medicine, Brigham and Women's Hospital and Harvard Medical School, 900 Commonwealth Ave, Boston, MA 02115, USA. Department of Cancer
Prevention and Control, Roswell Park Cancer Institute, Elm \& Carlton Streets, Buffalo, NY 14263, USA. ${ }^{8}$ Departamento de Patologia, A.C. Camargo Cancer Center, São Paulo, SP 01509-900, Brazil. ' Department of Medicine, University of Pittsburgh Medical Center, 300 Halket Street, Pittsburgh, PA 15213, USA.

${ }^{10}$ Department of Laboratory Medicine and Pathology, Mayo Clinic, 200 First Street SW, Rochester, MN 55905, USA. ${ }^{11}$ Dana-Farber Cancer Institute and Brigham and Women's Cancer Center, 450 Brookline Avenue, Boston, MA 02215, USA. ${ }^{12}$ Department of Obstetrics, Gynecology and Reproductive Sciences, University of Pittsburgh School of Medicine, 300 Halket Street, Pittsburgh, PA 15213, USA. ${ }^{13}$ Department of Health Sciences Research, Mayo Clinic, 200 First Street SW, Rochester, MN 55905, USA. ${ }^{14}$ Department of Nutrition, Harvard T.H. Chan School of Public Health, 677 Huntington Avenue, Boston, MA 02115, USA.

Received: 7 February 2017 Accepted: 31 August 2017 Published online: 12 September 2017

\section{References}

1. Jung $S$, Wang M, Anderson $K$, Baglietto $L$, Bergkvist $L$, Bernstein $L$, van den Brandt PA, Brinton L, Buring JE, Eliassen AH, et al. Alcohol consumption and breast cancer risk by estrogen receptor status: in a pooled analysis of 20 studies. Int J Epidemiol. 2016;45(3):916-28.

2. Smith-Warner SA, Spiegelman D, Yaun SS, van den Brandt PA, Folsom AR, Goldbohm RA, Graham S, Holmberg L, Howe GR, Marshall JR, et al. Alcohol and breast cancer in women: a pooled analysis of cohort studies. JAMA. 1998:279(7):535-40.

3. Chen WY, Rosner B, Hankinson SE, Colditz GA, Willett WC. Moderate alcohol consumption during adult life, drinking patterns, and breast cancer risk. JAMA. 2011;306(17):1884-90.

4. Li Cl, Chlebowski RT, Freiberg M, Johnson KC, Kuller L, Lane D, Lessin L, O'Sullivan MJ, Wactawski-Wende J, Yasmeen S, et al. Alcohol consumption and risk of postmenopausal breast cancer by subtype: the women's health initiative observational study. J Natl Cancer Inst. 2010;102(18):1422-31.

5. Dorgan JF, Baer DJ, Albert PS, Judd JT, Brown ED, Corle DK, Campbell WS, Hartman TJ, Tejpar AA, Clevidence BA, et al. Serum hormones and the alcohol-breast cancer association in postmenopausal women. J Natl Cancer Inst. 2001;93(9):710-5.

6. Reichman ME, Judd JT, Longcope C, Schatzkin A, Clevidence BA, Nair PP, Campbell WS, Taylor PR. Effects of alcohol consumption on plasma and urinary hormone concentrations in premenopausal women. J Natl Cancer Inst. 1993;85(9):722-7.

7. Seitz HK, Pelucchi C, Bagnardi V, La Vecchia C. Epidemiology and pathophysiology of alcohol and breast cancer: update 2012. Alcohol Alcohol. 2012:47(3):204-12.

8. Secretan B, Straif K, Baan R, Grosse Y, El Ghissassi F, Bouvard V, BenbrahimTallaa L, Guha N, Freeman C, Galichet L, et al. A review of human carcinogens - part E: tobacco, areca nut, alcohol, coal smoke, and salted fish. Lancet Oncol. 2009:10(11):1033-4.

9. Castro GD, Delgado de Layno AM, Fanelli SL, Maciel ME, Diaz Gomez MI, Castro JA. Acetaldehyde accumulation in rat mammary tissue after an acute treatment with alcohol. J Appl Toxicol. 2008;28(3):315-21.

10. Fanelli SL, Maciel ME, Diaz Gomez MI, Delgado de Layno AM, Bietto FM, Castro JA, Castro GD. Further studies on the potential contribution of acetaldehyde accumulation and oxidative stress in rat mammary tissue in the alcohol drinking promotion of breast cancer. J Appl Toxicol. 2011:31(1):11-9.

11. Liou GY, Storz P. Reactive oxygen species in cancer. Free Radic Res. 2010; 44(5):479-96.

12. Fuentes-Mattei E, Velazquez-Torres G, Phan L, Zhang F, Chou PC, Shin JH, Choi HH, Chen JS, Zhao R, Chen J et al. Effects of obesity on transcriptomic changes and cancer hallmarks in estrogen receptor-positive breast cancer. J Natl Cancer Inst. 2014;106(7)

13. Rotunno M, Sun X, Figueroa J, Sherman ME, Garcia-Closas M, Meltzer P, Williams T, Schneider SS, Jerry DJ, Yang XR, et al. Parity-related molecular signatures and breast cancer subtypes by estrogen receptor status. Breast Cancer Res. 2014;16(4):R74.

14. The Cancer Genome Atlas Network. Comprehensive molecular portraits of human breast tumours. Nature. 2012;490(7418):61-70.

15. Thomas G, Jacobs KB, Kraft P, Yeager M, Wacholder S, Cox DG, Hankinson SE, Hutchinson A, Wang Z, Yu K, et al. A multistage genome-wide association study in breast cancer identifies two new risk alleles at 1p11.2 and 14q24.1 (RAD51L1). Nat Genet. 2009;41(5):579-84. 
16. Tamimi RM, Baer HJ, Marotti J, Galan M, Galaburda L, Fu Y, Deitz AC, Connolly JL, Schnitt SJ, Colditz GA, et al. Comparison of molecular phenotypes of ductal carcinoma in situ and invasive breast cancer. Breast Cancer Res. 2008;10(4):R67.

17. Wang J, Zhang X, Beck AH, Collins LC, Chen WY, Tamimi RM, Hazra A, Brown M, Rosner B, Hankinson SE. Alcohol consumption and risk of breast cancer by tumor receptor expression. Horm Cancer. 2015;6(5-6):237-46.

18. Xu W, Seok J, Mindrinos MN, Schweitzer AC, Jiang H, Wilhelmy J, Clark TA, Kapur K, Xing Y, Faham M, et al. Human transcriptome array for highthroughput clinical studies. Proc Natl Acad Sci USA. 2011;108(9):3707-12.

19. Kauffmann A, Gentleman R, Huber W. arrayQualityMetrics - a bioconducto package for quality assessment of microarray data. Bioinformatics (Oxford, England). 2009;25(3):415-6.

20. Smyth GK. Linear models and empirical bayes methods for assessing differential expression in microarray experiments. Stat Appl Genet Mol Biol. 2004; 3 :Article3

21. Subramanian A, Tamayo P, Mootha VK, Mukherjee S, Ebert BL, Gillette MA Paulovich A, Pomeroy SL, Golub TR, Lander ES, et al. Gene set enrichment analysis: a knowledge-based approach for interpreting genome-wide expression profiles. Proc Natl Acad Sci USA. 2005;102(43):15545-50.

22. Wang K, Li M, Hakonarson H. Analysing biological pathways in genomewide association studies. Nat Rev Genet. 2010;11(12):843-54.

23. Wang K, Singh D, Zeng Z, Coleman SJ, Huang Y, Savich GL, He X, Mieczkowski P, Grimm SA, Perou CM, et al. MapSplice: accurate mapping of RNA-seq reads for splice junction discovery. Nucleic Acids Res. 2010;38(18):e178.

24. Li B, Dewey CN. RSEM: accurate transcript quantification from RNA-Seq data with or without a reference genome. BMC Bioinforma. 2011;12:323.

25. Robinson MD, Oshlack A. A scaling normalization method for differential expression analysis of RNA-seq data. Genome Biol. 2010;11(3):R25.

26. Romieu I, Scoccianti C, Chajes V, de Batlle J, Biessy C, Dossus L, Baglietto L, Clavel-Chapelon F, Overvad K, Olsen A, et al. Alcohol intake and breast cancer in the European prospective investigation into cancer and nutrition. Int J Cancer. 2015;137(8):1921-30.

27. Park SY, Kolonel LN, Lim U, White KK, Henderson BE, Wilkens LR. Alcohol consumption and breast cancer risk among women from five ethnic groups with light to moderate intakes: the Multiethnic Cohort Study. Int J Cancer. 2014;134(6):1504-10.

28. Hanahan D, Weinberg RA. Hallmarks of cancer: the next generation. Cell. 2011;144(5):646-74.

29. Blackinton JG, Keene JD. Post-transcriptional RNA regulons affecting cell cycle and proliferation. Semin Cell Dev Biol. 2014;34:44-54.

30. Fan S, Meng Q, Gao B, Grossman J, Yadegari M, Goldberg ID, Rosen EM. Alcohol stimulates estrogen receptor signaling in human breast cancer cell lines. Cancer Res. 2000;60(20):5635-9.

31. Singletary KW, Frey RS, Yan W. Effect of ethanol on proliferation and estrogen receptor-alpha expression in human breast cancer cells. Cancer Lett. 2001;165(2):131-7.

32. Candelaria NR, Weldon R, Muthusamy S, Nguyen-Vu T, Addanki S, Yoffou PH, Karaboga $\mathrm{H}$, Blessing AM, Bollu LR, Miranda RC, et al. Alcohol regulates genes that are associated with response to endocrine therapy and attenuates the actions of tamoxifen in breast cancer cells. PloS One. 2015:10(12):e0145061.

33. Lehrke M, Lazar MA. The many faces of PPARgamma. Cell. 2005;123(6): 993-9.

34. Dong JT. Anticancer activities of PPARgamma in breast cancer are contextdependent. Am J Pathol. 2013;182(6):1972-5.

35. Petersen RK, Larsen SB, Jensen DM, Christensen J, Olsen A, Loft S, Nellemann C, Overvad K, Kristiansen K, Tjonneland A, et al. PPARgamma-PGC-1alpha activity is determinant of alcohol related breast cancer. Cancer letters. 2012;315(1):59-68.

36. Musgrove EA, Sutherland RL. Biological determinants of endocrine resistance in breast cancer. Nat Rev Cancer. 2009;9(9):631-43.

37. Santen RJ, Yue W, Wang JP. Estrogen metabolites and breast cancer. Steroids. 2015;99(Pt A):61-6.

38. Ruggero D, Pandolfi PP. Does the ribosome translate cancer? Nat Rev Cancer. 2003;3(3):179-92

39. Crews FT, Bechara R, Brown LA, Guidot DM, Mandrekar P, Oak S, Qin L, Szabo G, Wheeler M, Zou J. Cytokines and alcohol. Alcohol Clin Exp Res. 2006;30(4):720-30.

40. Volpato S, Pahor M, Ferrucci L, Simonsick EM, Guralnik JM, Kritchevsky SB, Fellin R, Harris TB. Relationship of alcohol intake with inflammatory markers and plasminogen activator inhibitor-1 in well-functioning older adults: the Health, Aging, and Body Composition study. Circulation. 2004;109(5):607-12.
41. Esquivel-Velazquez M, Ostoa-Saloma P, Palacios-Arreola MI, Nava-Castro KE, Castro Jl, Morales-Montor J. The role of cytokines in breast cancer development and progression. J Interf Cytokine Res. 2015;35(1):1-16.

42. Nicolini A, Carpi A, Rossi G. Cytokines in breast cancer. Cytokine Growth Factor Rev. 2006;17(5):325-37.

43. Chavey C, Bibeau F, Gourgou-Bourgade S, Burlinchon S, Boissiere F, Laune $D$, Roques $S$, Lazennec $G$. Oestrogen receptor negative breast cancers exhibit high cytokine content. Breast Cancer Res. 2007;9(1):R15.

44. Buck MB, Knabbe C. TGF-beta signaling in breast cancer. Ann NY Acad Sci. 2006;1089:119-26.

45. Triano EA, Slusher LB, Atkins TA, Beneski JT, Gestl SA, Zolfaghari R, Polavarapu R, Frauenhoffer E, Weisz J. Class I alcohol dehydrogenase is highly expressed in normal human mammary epithelium but not in invasive breast cancer: implications for breast carcinogenesis. Cancer Res. 2003:63(12):3092-100

46. Kedishvili NY, Stone CL, Popov KM, Chernoff EA. Role of alcohol dehydrogenases in steroid and retinoid metabolism. Adv Exp Med Biol. 1997:414:321-9.

47. Tang XH, Gudas LJ. Retinoids, retinoic acid receptors, and cancer. Annu Rev Pathol. 2011;6:345-64

48. Goeman JJ, Buhlmann P. Analyzing gene expression data in terms of gene sets: methodological issues. Bioinformatics (Oxford, England). 2007:23(8):980-7.

49. Abdueva D, Wing M, Schaub B, Triche T, Davicioni E. Quantitative expression profiling in formalin-fixed paraffin-embedded samples by affymetrix microarrays. J Mol Diagn. 2010;12(4):409-17.

50. Ali AM, Schmidt MK, Bolla MK, Wang Q, Gago-Dominguez M, Castelao JE, Carracedo A, Garzon VM, Bojesen SE, Nordestgaard BG, et al. Alcohol consumption and survival after a breast cancer diagnosis: a literature-based meta-analysis and collaborative analysis of data for 29,239 cases. Cancer Epidemiol Biomarkers Prev. 2014;23(6):934-45.

51. Seitz HK, Stickel F. Molecular mechanisms of alcohol-mediated carcinogenesis. Nat Rev Cancer. 2007;7(8):599-612.

\section{Submit your next manuscript to BioMed Central and we will help you at every step:}

- We accept pre-submission inquiries

- Our selector tool helps you to find the most relevant journal

- We provide round the clock customer support

- Convenient online submission

- Thorough peer review

- Inclusion in PubMed and all major indexing services

- Maximum visibility for your research

Submit your manuscript at www.biomedcentral.com/submit
) Biomed Central 